\title{
Study of genetic variability for morphological traits in bread wheat across sowing dates
}

Muhammad Babar ${ }^{*}$, Salman $\mathrm{Ali}^{2}$, Fazale $\mathrm{Akbar}^{1}$, Mushtaq $\mathrm{Ali}^{1}$, Muhammad Uzair ${ }^{1}$, Ghani Subhan ${ }^{3}$, Jihad Ali ${ }^{1}$ and Hassan Khan ${ }^{4}$

1. Department of Agriculture, University of Swabi-Anbar, Swabi-Khyber Pakhtunkhwa, Pakistan

2. Cereal Section, Agricultural Research Institute, Tarnab-Peshawar, Khyber Pakhtunkhwa, Pakistan

3. Department of Plant Breeding and Genetics, The University of Agriculture, Peshawar, Pakistan

4. Department of Soil and Environmental Sciences, The University of Agriculture, Peshawar, Pakistan

*Corresponding author's email: babarkhanuos@gmail.com

Citation

Muhammad Babar, Salman Ali, Fazale Akbar, Mushtaq Ali, Muhammad Uzair, Ghani Subhan, Jihad Ali and Hassan Khan. Study of genetic variability for morphological traits in bread wheat across sowing dates. Pure and Applied Biology. Vol. 11, Issue 3, pp843-850. http://dx.doi.org/10.19045/bspab.2022.110086

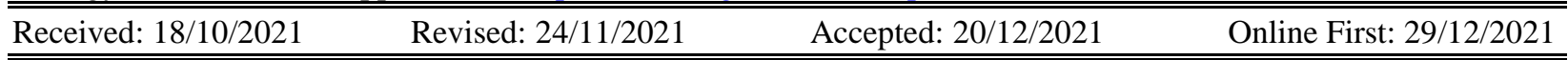

\section{Abstract}

The research was carried out with the objective to estimate genetic variability for morphological traits in wheat. Twenty wheat genotypes along with 2 checks were planted at Cereal Section Research Institute (CCRI) Pirsabak under two sowing dates. Analysis of variance revealed highly significant differences among genotypes for majority of the traits. Mean days to heading ranged from 106 to 113, days to maturity ranged from 145 to 151 days, plant height ranged from 92 to $108 \mathrm{~cm}$, grain yield per hectare ranged from 2117 to $3984 \mathrm{~kg} \mathrm{ha}^{-1}$ and biological yield ranged from 8611 to $11250 \mathrm{~kg} \mathrm{ha}^{-1}$. Genetic and phenotypic variances were greater than environmental variances for all the traits however; genetic, phenotypic and environmental variances were almost minor $(20.10,24.03$ and 2.19) for days to maturity and maximum (3354401.62, 5824977.32 and 908395.70) for biological yield, respectively. However, interaction between genotypes and sowing dates were almost negligible (1.74) for days to maturity and maximum (1562179.99) for biological yield. Regarding coefficients of variation (CV), values ranged from 0.85 to 9.28 for tested traits. According to mean performance, the genotypes viz., PS-23, PS-33, PS-34 and PS-28 showed high performance. However, the genotype Inq-91/FS(f8) was found to be the most stable in performance in both conditions and therefore, these genotypes could be used in future wheat breeding programs to enhance the grain yield in bread wheat.

Keywords: Genetic variability; Grain yield; Genetic and phenotypic variability; Bread wheat

\section{Introduction}

Wheat, a winter cereal commonly used as a staple food [1]. It provides food to $36 \%$ of the global population and contributes towards $20 \%$ food calories. It feeds $36 \%$ of the world population and contributes $20 \%$ of all food calories. Wheat is a major cereal crop farmed on more than 240 million hectares (ha) around the world, more than any other crop. Wheat has more hectares in the world than all other crops combined [2]. Wheat is the most important source of vegetable protein in human food, with higher protein content than corn, rice, and other major cereals 
worldwide. By 2020, the world's wheat demand is expected to be between 840 and 1000 million tonnes [3].

Wheat can be cultivated under both the irrigated as well as rainfed conditions [4]. Approximately, 8.74 million hectares of wheat crop were planted in Pakistan in 20182019. Wheat was planted on 0.74 million hectares in Khyber Pakhtunkhwa in 20182019, yielding 1.36 million tonnes with a total production of $1860 \mathrm{~kg} \mathrm{ha}^{-1}$ [5].

Climate change, a growing scarcity of water resources, and a deteriorating environment had a significant impact on wheat production [6]. One of the major causes of wheat yield decline is the cultivation of varieties of low genetic potential [7]. Wheat breeders are focussing their efforts to improve yield variability by producing new high yielding varieties with favourable genetic makeup in order to boost wheat output. The genetic potential of diverse genotypes of distinct morpho-yield traits is essential for a successful breeding program [8].

Variability refers to the occurrence of variances among individuals as a result of differences in their genetic makeup and upbringing. If the character expression of two people could be assessed in the same environment, the differences in expression would be due to genetic control, and this variation would be referred to as genetic variation [9]. Genetic variability, which arises from genetic variances among individuals in a population, is at the part of plant breeding because good variety management can result in long-term improvements in plant performance as well as seasonal changes [10]. To support and sustain a successful long-term wheat breeding program, genetic diversity, is necessary on a significant level within a population. The magnitude of genetic diversity in the population has been observed to be closely related to selection progress [11]. In the original accessions and races across sampled populations representing various climatic and geographical locales, a significant level of genetic variability has been observed [12].

In light of the foregoing facts and figures, the current research was carried out with the following objectives: 1: to assess the extent of genetic variability in bread wheat genotypes. 2: Genotype $\times$ sow dates interaction in wheat cultivars. 3: for the estimation of coefficient of variation.

\section{Materials and Methods}

\section{Experimental site, material and design}

The study was conducted during 2015-2016 at the Cereal Crops Research Institute (CCRI) Pirsabak Nowshera, located at 340 North Latitude, 720 East Longitude, and 2880 Altitude. Twenty wheat genotypes, including two checks (Pakhtunkhwa-2015 and Pirsabak-13), were planted in a randomized complete block design (RCBD) with three replications on two different sowing dates: normal sowing November $24^{\text {th }}$ and late sowing December $25^{\text {th }}, 2015$. A plot of $9 \mathrm{~m}^{2}$ area was used having four rows of 1.5 meters length and $30 \mathrm{~cm}$ apart. The paternal genotypes are detailed in (Table 1). From sowing to harvesting, all agronomic practices were applied uniformly.

\section{Data collection}

Data was collected on the following parameters using a standard approach specified by several writers and researchers. Days to heading were counted from the time of seeding to the time when $50 \%$ of the plants had finished heading. Days to maturity were calculated as the number of days when 90 percent of the plants in a plot reach physiological maturity. Plant height was measured in $\mathrm{cm}$ from the soil surface to the top of the spike, excluding awns, at physiological maturity. Grain yield was recorded in each subplot by harvesting the material, sun dried and threshed separately and was converted to $\mathrm{kg} \mathrm{ha}^{-1}$. At maturity, each plant was harvested separately and 
weighed with an electronic scale before threshing to determine biological yield.

\section{Statistical analysis}

Micro Soft excel was used to statistically evaluate the data relevant to the aforesaid characters. In addition, the analysis of variances package is given below (Table 2).

\section{Estimation of genetic variability}

The genotypic, phenotypic and environmental variances were calculated by the following formulas:

Genetic variance $(\mathrm{Vg})=\frac{M 1-M 2}{R S D}$

$\mathrm{VG} \times \mathrm{SD}=\frac{M 2-M 3}{R}$

While, environmental Variance $(\mathrm{Ve})$ is $\mathrm{M}_{3}$ and $\mathrm{VP}=\mathrm{VG}+\mathrm{VG} \times \mathrm{SD}+\mathrm{VE}$

\section{Results}

Days to heading

Combined analysis of variance stated that mean square depicts significant differences among different genotypes and sowing dates, while genotype $\times$ sowing dates interaction was found non-significant for days to heading (Table 3). Minimum days to heading (106) were recorded for CDRI-SA-12 and DN-123 followed by SRN-13121 and PS-23 (107). Similarly, Maximum days (113 days) to heading were observed for CDRI-PV-1, followed by PS-34 and DN-120 with 112 and 112 days to heading, respectively (Table 4). Similarly, phenotypic variance (31.66) and genetic variance (25.97) were greater than environmental variance (3.22) and genotype $\times$ sowing dates interaction (2.48) for days to heading and coefficients of variance (1.40) which indicated of genotypic variability for days to heading (Table 5).

\section{Days to maturity}

Combine analysis of variance for days to maturity stated that mean square showed significant differences between different genotypes and sowing dates, while genotype $x$ sowing dates interaction was found nonsignificant (Table 3). Therefore, the minimum days to maturity (145) was reported for DN-123 followed by Pirsabak13, CDRI-PV-2 and CDRI-SA-12. Similarly, maximum days (151) to maturity were observed for PS-28, followed by CT-13169 and PS-34 with the same 150 days to maturity, as respectively (Table 4). Likewise, phenotypic variance (24.03) and genetic variance (20.10) was greater than environmental variance (2.19) and genotype $\times$ sowing dates interaction (1.74) for days to maturity and coefficients of variance $(0.85)$ showed narrow range of genotypic variability along with less influence of environment for the expression of days to maturity (Table 5).

\section{Plant height}

Mean square showed significant differences among different genotype and sowing dates $(p \leq 0.001)$ for plant height while the interaction for genotype $\times$ sowing dates was also found highly significant as evident from the analysis of variance in mean square (Table 3). Mean data for plant height varied from 91.50 to 108.00. Maximum plant height $(108 \mathrm{~cm})$ was observed in genotype PS-28, while genotype Pirsabak-13 was recorded minimum for plant height (91.50) (Table 4). Furthermore, Phenotypic variance $(165.16 \mathrm{~cm})$ and genetic variance $(131.45 \mathrm{~cm})$ was greater than environmental variance $(10.41 \mathrm{~cm})$ and genotype $\times$ sowing dates interaction was (23.30) for plant height and coefficients of variance for the said attribute was (2.74) (Table 5).

\section{Biological yield}

The (Table 3) showed that biological yield was significantly affected by sowing dates, genotypes and the interaction between $\mathrm{G} \times$ $\mathrm{SD}$. The mean range for biological yield was ranging between 8611.11 to $11250.00 \mathrm{~kg} \mathrm{ha}^{-}$ ${ }^{1}$. Among the genotypes maximum biological yield was observed for PS-23 $(11250.00 \mathrm{~kg}$ $\mathrm{ha}^{-1}$ ) followed by SRN-13121 (10972.22 kg $\mathrm{ha}^{-1}$ ), while minimum was recorded for AUP07014 (8611.11) followed by CDRI-SA-12 (8750.00). However, the remaining genotypes showed medium performance for the said attribute (Table 4). Moreover, phenotypic variance (5824977.32) and 
genetic variance (3354401.62) was greater than environmental variance (908395.70) and genotype $\times$ sowing dates interaction (1562179.99) for plant height and coefficients of variance (8.00) showed the genotypic variability along with less influence of environment for the expression of the said trait (Table 5).

\section{Grain yield per plant}

The mean square for grain yield depicts highly significant variation due to genotypes in two sowing dates and genotype $\times$ sowing dates interaction was also found highly significant (Table 3). This suggested that the magnitude of differences in genotypes was sufficient to provide some scope for selecting genotypes with improved heat stress tolerance. The main effect of sowing dates regimes and the interaction between genotypes $\times$ sowings dates regimes were highly significant for the measured traits. Grain yield of genotypes varied, particularly under stress conditions, the average grain yield was recorded in all wheat genotypes which ranged between 2116.67 to 3983.89. Among all the genotypes, maximum grain yield was observed for PS-34 (3983.89), followed by PS-23 (3786.67). Similarly, minimum was reported for CDRI-SA-12 (2116.67). However, the remaining genotypes showed medium performance for the said attribute (Table 4). Moreover, phenotypic variance (1603499.81) and genetic variance (1117393.60) was greater than environmental variance (125365.31) and genotype $\times$ sowing dates interaction (360740.90) for plant height and coefficients of variance (9.28) showed the high of genotypic variability along with less influence of environment for the expression of the said trait (Table 5).

\section{Discussion}

Plant breeders are interested in developing novel wheat genotypes with early maturity since it is desirable. As a result of the delayed heading, there is less time for grain filling, resulting in lesser grain weight. Earlyheading genotypes can have a longer grain filling period, allowing them to finish a higher portion of the grain filling earlier in the season when air temperatures are cooler and more suitable for wheat [13]. Our results are in line with [14] who reported genotypic (27.01) and phenotypic variance (29.58) for days to heading. Further our results are also in conformity with those reported by [15]. Physiological maturity in grains crops refers to the attainment of maximum seed dry weight. Because the crop is prone to several sources of stress such as lodging, pre-harvest sprouting, hail, and biological challenges, knowing when the crop reaches physiological maturity is critical in particular situations [16]. Our result of days to maturity was not in line with [17] who reported genotypic and phenotypic variance respectively. Our results were different and high genotypic, phenotypic and environment variation found because our genotypes evaluated at two sowing dates. Our results are contradictory to [18] who reported environmental, phenotypic, and genotypic and (CV) coefficient of variances for days to maturity, respectively.

Wheat breeding programs use plant height as a crucial criterion. Short stature genotypes are chosen by plant breeders because they help increase lodging resistance and respond well to nutrients and irrigation in wheat [19]. Because taller plants are more likely to lodge and require more energy to transmit photosynthates to the grains in wheat [20], shorter plants are necessary. According to genotypic variance (Vg) and phenotypic variation (Vp) our calculated variation was not matching to [21] who reported the genotypic, phenotypic and environmental variance, respectively. Likewise, our finding was not similar to [22]. Results further revealed that plant height might be an effective trait to select higher yielding genotypes. Our result was different from [23] 
who reported a high level of genotypic and environmental variance.

In our results of biological yield genetic, phenotypic, environmental and (CV) coefficient of variance is not similar to [24]. Similarly, our results were different from [25] who reported phenotypic, genotypic, environment and coefficient of variance for biological yield. Grain yield is a complicated feature, and plant breeders are primarily concerned in developing high-yielding genotypes to meet the countries food requirement. In wheat plant breeding projects, differences in genotypes for grain yield and yield-related traits are the most important concern [26]. The magnitude of difference between $\mathrm{VG}, \mathrm{VP}, \mathrm{VG} \times \mathrm{SD}, \mathrm{VE}$ and $\mathrm{CV}$ was relatively high for grain yield. This implies greater influence of environmental factors for the phenotypic expression of these characters that make difficult or practically impossible to exercise selection based on phenotypic performance of the genotypes to improve the characters. In our results genetic variance and phenotypic variance for grain yield was greater than environmental variance. My result was opposite to [27] who reported environmental, genotypic and phenotypic variance for grain yield.

Wheat genotypes yielded dramatically different amounts of grain in both conditions. As a result, the overall scenario revealed that genetic variability plays a substantial role, implying the use of integrated heat stress breeding strategies that might possibly harness additive and non-additive genetic variability under normal and heat stress conditions.

Table 1. List of wheat genotypes along with station and parentage used in study during 201516 at CCRI, Pirsabak Nowshera

\begin{tabular}{|c|c|c|c|c|c|}
\hline S. No. & Genotypes & Breeding Station & S. No. & Genotypes & Breeding Station \\
\hline 1. & Inq-91/FS(f8) & NIFA Pesh. & 11. & PS-33 & CCRI Pirsabak \\
\hline 2. & SRN-13121 & NIFA Pesh. & 12. & PS-34 & CCRI Pirsabak \\
\hline 3. & CT-13052 & NIFA Pesh. & 13. & PS-35 & CCRI Pirsabak \\
\hline 4. & CT-13169 & NIFA Pesh. & 14. & AUP-05814 & PBG (UAP) \\
\hline 5. & DN-120 & ARI D.I. Khan & 15. & AUP-07014 & PBG (UAP) \\
\hline 6. & DN-122 & ARI D.I. Khan & 16. & CDRI-PV-1 & NARC Islamabad \\
\hline 7. & DN-123 & ARI D.I. Khan & 17. & CDRI-PV-2 & NARC Islamabad \\
\hline 8. & PS-22 & CCRI Pirsabak & 18. & CDRI-SA-12 & NARC Islamabad \\
\hline 9. & PS-23 & CCRI Pirsabak & 19. & Pakhtunkhwa-2015 & CCRI Pirsabak \\
\hline 10. & PS-28 & CCRI Pirsabak & 20. & Pirsabak-13 & CCRI Pirsabak \\
\hline
\end{tabular}

Table 2. Analysis of variance model used for 20 bread wheat genotypes, evaluated during the year 2015-16 at CCRI, Pirsabak Nowshera

\begin{tabular}{|c|c|c|}
\hline Source of variation & Mean square & Expected mean square \\
\hline Sowing Date (SD) & M1 & -------- \\
\hline Replication (SD) & M2 & ------- \\
\hline Genotype (G) & M3 & Ve + Vgsd + rsd Vg \\
\hline G $\times$ SD & M4 & Ve +rVgsd \\
\hline Error & M5 & ----- \\
\hline Total & & \\
\hline
\end{tabular}


Table 3. Mean sum of square for days to heading (DH), days to maturity (DM), plant height (PH), biological yield (BY) and grain yield (GY) of 20 wheat genotypes including two checks cultivars evaluated two sowing dates during the year 2015-16 at CCRI, Pirsabak Nowshera

\begin{tabular}{|c|c|c|c|c|c|c|}
\hline SOV & DF & DH & DM & PH & BY & GY \\
\hline SD & 1 & 11880.30 & 28152.03 & 2557.63 & 442368000.00 & 43882675.93 \\
\hline Rep/SD & 4 & 4.54 & 2.88 & 14.69 & 988444.44 & 392794.26 \\
\hline Gen & 19 & 26.75 & 20.96 & 133.27 & 3354403.51 & 1117394.62 \\
\hline G x SD & 19 & 3.55 & 2.47 & 26.77 & 1864978.56 & 402529.34 \\
\hline Error & 76 & 3.22 & 2.19 & 10.41 & 908395.71 & 125365.31 \\
\hline
\end{tabular}

Table 4. Pooled mean performance of twenty wheat genotypes evaluated in two different sowing dates with two checks for various characters, and at CCRI Pirsabak Nowshera during 2015-16

\begin{tabular}{|c|c|c|c|c|c|}
\hline Genotypes & $\begin{array}{c}\text { Days to } \\
\text { heading }\end{array}$ & $\begin{array}{c}\text { Days to } \\
\text { maturity }\end{array}$ & Plant height & Biological yield & Grain yield \\
\hline Inq-91/FS(f8) & 109 & 149 & 93.67 & 9427.78 & 3388.89 \\
\hline SRN-13121 & 107 & 148 & 99.83 & 10972.22 & 3231.67 \\
\hline CT-13052 & 108 & 147 & 102.00 & 10138.89 & 3401.67 \\
\hline CT-13169 & 112 & 151 & 92.83 & 9722.22 & 3186.67 \\
\hline DN-120 & 112 & 149 & 100.67 & 8972.22 & 2824.44 \\
\hline DN-122 & 108 & 148 & 95.83 & 9722.22 & 3067.78 \\
\hline DN-123 & 107 & 145 & 100.00 & 10694.44 & 3457.78 \\
\hline PS-22 & 110 & 151 & 100.67 & 10555.56 & 3577.78 \\
\hline PS-23 & 107 & 147 & 107.33 & 11250.00 & 3786.67 \\
\hline PS-28 & 109 & 151 & 108.00 & 10833.33 & 3653.33 \\
\hline PS-33 & 108 & 147 & 107.83 & 10416.67 & 3335.00 \\
\hline PS-34 & 112 & 151 & 99.00 & 10555.56 & 3983.89 \\
\hline PS-35 & 106 & 148 & 101.83 & 10555.56 & 3372.22 \\
\hline AUP-05814 & 110 & 148 & 99.67 & 10000.00 & 2846.67 \\
\hline AUP-07014 & 111 & 150 & 96.50 & 8611.11 & 2636.11 \\
\hline CDRI-PV-1 & 113 & 150 & 99.83 & 10277.78 & 2842.78 \\
\hline CDRI-PV-2 & 108 & 146 & 99.17 & 10694.44 & 3440.56 \\
\hline CDRI-SA-12 & 106 & 146 & 103.50 & 8750.00 & 2116.67 \\
\hline Pakhtunkhwa-2015 & 108.00 & 147.33 & 105.33 & 10694.44 & 3541.67 \\
\hline Pirsabak-13 & 107.67 & 145.67 & 91.50 & 9722.22 & 3178.89 \\
\hline LSD at 5\% & 2.26 & 1.86 & 4.08 & 1200.65 & 446 \\
\hline
\end{tabular}

Table 5. Genetic variability, genotypic, phenotypic and environmental variance and genotype $\times$ sowing dates interaction for days to heading $(\mathrm{DH})$, day to maturity $(\mathrm{DM})$, plant height (PHT), biological yield (BY) and grain yield (GY) of 20 genotypes including two checks cultivars evaluated during the year 2015-16 at CCRI, Pirsabak Nowshera

\begin{tabular}{|c|c|c|c|c|c|}
\hline Traits & DH & DM & PHT & BY & GY \\
\hline VG & 25.97 & 20.10 & 131.45 & 3354401.62 & 1117393.60 \\
\hline VGSD & 2.48 & 1.74 & 23.30 & 1562179.99 & 360740.90 \\
\hline VP & 31.66 & 24.03 & 165.16 & 5824977.32 & 1603499.81 \\
\hline VE & 3.22 & 2.19 & 10.41 & 908395.70 & 125365.31 \\
\hline CV & 1.40 & 0.85 & 2.74 & 8.00 & 9.28 \\
\hline
\end{tabular}




\section{Conclusion}

Analysis of variance showed highly significant differences for majority of the traits, and showed greater genetic variability and hence can be used for upgrading of obtainable cultivars or releasing as new variety. Almost all the traits were found highly genetic variance and genotype $\times$ sowing dates interaction suggested that improvement for most of the yielding traits is possible in early generation of selection. The tested genotypes in stress and non-stress conditions Inq-91/FS(f8), AUP-05814, PS34 and PS-28 were identified as superior lines for future wheat breeding programs and could be released as new tolerant and resistant variety to biotic and abiotic stress after multi-location trials.

\section{Authors' contributions}

Conceived and designed the experiments: $\mathrm{M}$ Uzair \& H Khan, Performed the experiments: M Ali \& G Subhan, Analyzed the data: F Akbar \& J Ali, Contributed materials/ analysis/ tools: S Ali, Wrote the paper: $\mathrm{M}$ Babar.

\section{Acknowledgement}

The research was successfully completed with the great help of my co-authors, specially thanks to Durrishahwar and Hidayat Ullah. In addition, especially thanks to Muhammad Ishaq and Khilwat Afridi and Cereal Section Research Institute (CCRI) Pirsabak for giving me the land for this research.

\section{References}

1. Mollasadeghi V \& Shahryari R (2011). Important morphological markers for improvement of yield in bread wheat. $A d v$ Environ Biol 5(3): 538-542.

2. Curtis BC (1982). Potential for a yield increase in wheat. In Proc. Natl. Wheat Res. Conf., Beltsville, MD, USA, 26-28 Oct., p. 5-19. Washington, DC, National Association of Wheat Growers Foundation.
3. Rosegrant MW, Paisner M, Meijer S \& White cover J. (2001). Global Food Projections to 2020: Emerging Trends and Alternative Futures. Washington, DC. IFPRI.

4. Siddiqui KA (2008). Coping with wheat in Pakistan in the wake of green biotechnology, nano biotechnology and food sovereignty. In: 11th Intl. Wheat Genetics Symposium, Brisbane, Australia.

5. PBS. (2018-19). Pakistan Bureau of Statistics (PBS), Ministry of Finance, Government of Pakistan (www.finance.gov.pk).

6. Singh G \& Chaudhary H (2006). Selection parameters and yield enhancement of wheat (Triticum aestivum L.) under different moisture stress condition. Asian J Plant Sci 5: 894-898.

7. Nasim SA, Mujib A, Kapoor R, Fatima S \& Aslam J (2010). Somatic embryogenesis in Allium sativum L. (cv. Yamuna safed 3): Improving embryo maturation and germination with PGRs and carbohydrates. In Anales de Biol 32: 1-9.

8. Ahmad B, Khalil IH, Iqbal M \& Rahman H (2010). Genotypic and phenotypic correlation among yield components in bread wheat under normal and late plantings. Sarhad J Agric 26(2): 259-265.

9. Falconer DS, Trudy FC \& Mackay (1996). Introduction to Quantitative Genetics. 4th ed., Longman Group Limited, Malaysia, pp. 464.

10. Welsh JR (1981). Fundamentals of plant genetics and breeding, John willey and Sons.

11. Hallauer AR \& Miranda JB (1995). Quantitative genetics in maize breeding. 2nd Ed. Ames: Iowa State University Press, pp. 468.

12. Illarslan R, Kaya Z, Kandemir I \& Bretting PK (2002). Genetic variability among Turkish population, Flint and dent corn (Zea mays spp. mays) races; 
Morphological and agronomic traits. Euphytica 128(2): 173-182.

13. Tewolde H, Fernandez CJ \& Erickson CA (2006). Wheat cultivars adapted to postheading high temperature stress. Agron Crop Sci 192: 111-120.

14. Rohani SN \& Shailesh (2016). Evaluation of genetic variability for some quantitative traits in wheat (Triticum aestivum L.). Inter J of Multidisciplinary Res and Devel 3(7): 12-14.

15. Dutamo D, Alamerew S, Eticha F \& Assefa E (2015). Genetic variability in Bread Wheat (Triticum aestivum L.) Germplasm for Yield and Yield Component Traits. J of Biol, Agric and Healthcare, 5(17): 140-147.

16. Calderini DF \& Reynolds MP (2000). Changes in grain weight as a consequence of de-graining treatments at pre-and postanthesis in synthetic hexaploid lines of wheat (Triticum durum x T. tauschii). Func Plant Biol 27(3): 183-191.

17. Afridi K, Ahmad, Ishaq M, Khalil IA, Shah IA, Saeed M \& Ahmad N (2014). Genetic potential and variability for morpho-yield traits in durum wheat (Triticum turgidum L.). Var. Durum). Inter J Farm and Alli Sci 3(12): 12061212.

18. Khan I, Mohammad F \& Khan FU (2015). Estimation of genetic parameters of yield and yield traits in wheat genotypes under rainfed conditions. Inter J of Environ 4(2): 193-205.

19. Khan, AJ Azam F \& Ali A (2010). Relationship of morphological traits and grain yield in recombinant inbred wheat lines grown under drought conditions. Pak $J$ Bot 42(1): 259-267.

20. Çifci EA (2012). Estimate of heterosis, correlation and path analysis for grain yield per spike and some agronomic traits on durum wheat (T. durum Desf). J Anim Plant Sci 22(3): 747-752.

21. Salman S, Khan SJ, Khan J \& Ullah R (2014). Genetic variability studies in bread wheat (Triticum aestivum L.) Accessions. Pak J Agric Res 27(1).

22. Degewione A, Dejene $\mathrm{T} \&$ Sharif $M$ (2013). Genetic variability and traits association in bread wheat (Triticum aestivum L.) genotypes. Inter Res $J$ of Agric Sci 1(2): 19-29.

23. Sharaan AA, Kamal HG \& Abdel SE (2017). Estimation of Genetic Parameters for yield and its components in bread wheat (Triticum aestivum L.) genotypes under pedigree selection. Inter J of Agron and Agric Res 10(2): 22-30.

24. Ghallab KH \& Sharran AAN (2016). Genetic parameters for yield and yield components traits of some wheat genotypes grown in newly reclaimed soils. Inter J of Agron and Agric Res (IJAAR). 9(4): 1-8.

25. Jan S, Mohammad F \& Khan FU (2015). Genetic potential and heritability estimates of yield traits in $\mathrm{F}_{3}$ segregating populations of bread wheat. Inter $J$ of Environ 4(2): 106-115.

26. Talebi R, Fayaz F \& Naji AM (2009). Effective selection criteria for assessing drought stress tolerance in durum wheat (T. durum L.). J and Appl Plant Physiol 35(1/2): 64-74.

27.Asaye DL, Desalegn T \& Alemayehu G (2013). Genetic variation of bread wheat (Triticum aestivum L.) genotypes based on number of phonological and morphological traits at Marwold Kebele, Womberma Woreda, West Gojam. Wudpecker J of Agric Res 2(6): 160-166. 